\title{
A Decision Method of Cogeneration Operation Schedule by Combining Use of SOFCs and PEFCs
}

\author{
Shoji Kawasaki and Soma Tange \\ Department of Electronics and Bioinformatics, School of Science and Technology, Meiji University, Kanagawa 2148571, Japan
}

\begin{abstract}
In this paper, the authors propose a cogeneration system by combining two kinds of FCs (fuel cells) for a collective housing. The good points which each FC has are applied to the cogeneration operation schedule. In this study, some rooms interchange electric power and heat with each other for high efficiency and reduction of energy loss. The authors determine an operation schedule of FCs by multi-evaluation from viewpoints of energy cost and $\mathrm{CO}_{2}$ emissions.
\end{abstract}

Key words: FC, cogeneration system, optimization, operation schedule, interchange of power and heat.

\section{Introduction}

Cogeneration which can supply electric power and heat simultaneously has received a lot of attention in recent years, against the background of energy exhaustion and global environmental problems [1-3].

In this paper, the authors propose a cogeneration system which combines SOFC (solid oxide fuel cell) and PEFC (polymer electrolyte FC). The good point of SOFC is high efficiency of electric power generation and PEFC is high efficiency of exhaust heat recovery. Although PEFC is used mainly in housing in this day, the authors believe that combined use of SOFC and PEFC will enable more efficient interchange of power and heat.

In addition, the authors investigate the cogeneration operation schedule in which energy cost and $\mathrm{CO}_{2}$ emissions are minimized by combining use of SOFC and PEFC in consideration of heat interchange, and propose a decision method of the operation schedule. In order to verify the validity of the proposed system, the numerical calculations are carried out for the collective housing model and the cogeneration operation schedules for every season are determined.

Corresponding author: Shoji Kawasaki, associate professor, research fields: advancement of electric power system, improvement of electric power quality.

\section{Determination of Operation Schedule of SOFCs and PEFCs in Collective Housing}

\subsection{Collective Housing with SOFCs and PEFCs}

Fig. 1 shows an electric power and heat interchange system using SOFCs and PEFCs in a collective housing. The operation schedule of FCs is determined in one unit (here, four rooms). Fig. 2 shows the interchange of electric power and heated water in the unit. SOFCs and PEFCs are installed in a common space. Each room interchanges the electric power and heated water. Fig. 3 shows a flow of electric power, gas, and heated water in each room. If the electric power fails, the consumers buy it from a utility grid. And if the electric power surplus, the consumers can sell it which only SOFCs generate by the deregulation of electric power in Japan. About demand and supply of heat, in case of the heated water shortage, a gas boiler supplies it. In case of the heated water surplus, it is effectively used by a washing machine.

\subsection{Definition and Formulation for Determination of SOFCs and PEFCs Operation Schedule}

In this study, the purpose of determining cogeneration operation schedule for FCs is to minimizethe energy cost and $\mathrm{CO}_{2}$ emissions. This is a decision problem which determines the start-and-stop 


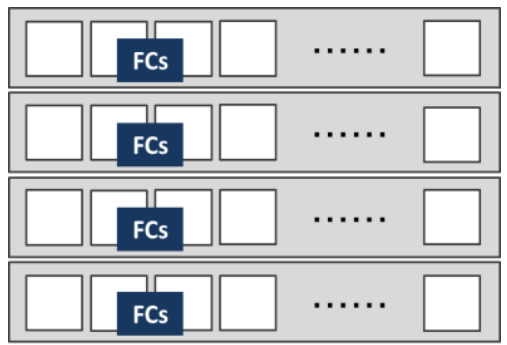

Fig. 1 Collective housing with FCs.

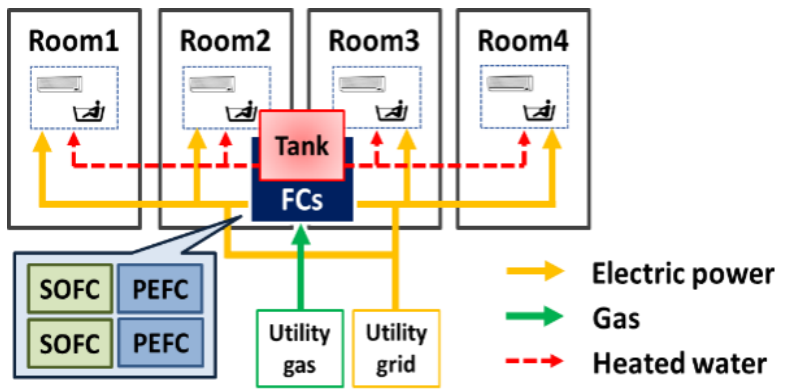

Fig. 2 One unit in collective housing.

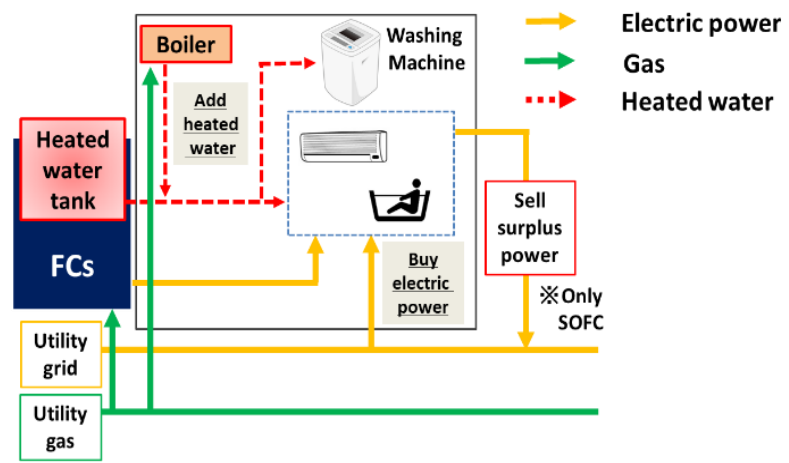

Fig. 3 Flow of each energy in a room.

and output schedule of each FC which satisfies all of seven constraints shown below, where, the output of FCs is dealt with as a discrete value. The objective function and constraints are shown in Eqs. (1)-(13).

Objective function of main problem:

$$
\begin{array}{r}
F(\alpha)=\sqrt{\left(1-F_{\text {COST }}\left(x_{\alpha}, p_{\alpha}\right)\right)^{2}+\left(1-F_{C O 2}\left(x_{\alpha}, p_{\alpha}\right)\right)^{2}} \\
\rightarrow \text { minimize }
\end{array}
$$

Objective function of partial problem:

$$
\begin{gathered}
f\left(x_{\alpha}, p_{\alpha}\right)=\alpha \cdot F_{C O S T}\left(x_{\alpha}, p_{\alpha}\right)+(1-\alpha) \cdot F_{C O 2}\left(x_{\alpha}, p_{\alpha}\right) \\
\rightarrow \text { minimize } \\
F_{C O S T}\left(x_{\alpha}, p_{\alpha}\right)=\frac{f_{C O S T}\left(x_{\alpha}, p_{\alpha}\right)}{\min \left\{f_{C O S T}\right\}} \\
F_{C O 2}\left(x_{\alpha}, p_{\alpha}\right)=\frac{f_{C O 2}\left(x_{\alpha}, p_{\alpha}\right)}{\min \left\{f_{C O 2}\right\}}
\end{gathered}
$$

$$
\begin{gathered}
f_{\text {COST }}\left(x_{\alpha}, p_{\alpha}\right)=\sum_{t=1}^{T} P_{S Y S t} \cdot \operatorname{Cost}_{P}+\sum_{i=1}^{N_{S}} \sum_{t=1}^{T} G_{S i t}\left(x_{\alpha}, p_{\alpha}\right) \cdot \text { Cost }_{G} \\
+\sum_{i=1}^{N_{P}} \sum_{t=1}^{T} G_{P i t}\left(x_{\alpha}, p_{\alpha}\right) \cdot \operatorname{Cost}_{G}-\sum_{t=1}^{T} P_{\text {SURt }} \cdot \text { Cost }_{p s} \\
f_{C O 2}\left(x_{\alpha}, p_{\alpha}\right)=\sum_{t=1}^{T}\left\{K_{G} \cdot\left(\sum_{i=1}^{N_{S}} x_{\text {Soit }} \cdot p_{\text {Soit }}+\sum_{i=1}^{N_{P}} x_{\text {Poit }} \cdot p_{\text {Poit }}\right)\right. \\
\left.+K_{E} \cdot P_{S Y S t}+B_{\text {CO } 2 i t}\right\}
\end{gathered}
$$

Constraints:

$$
\begin{gathered}
\sum_{i=1}^{N}\left\{P_{\text {LOADit }}+P_{\text {Sit }}\left(x_{\text {Soit }}\right)+P_{\text {Pit }}\left(x_{\text {Poit }}\right)\right\} \\
\sum_{t=1}^{T}\left(x_{\text {Sait }}-x_{\text {Soit }-1}\right) x_{\text {Sait }} \leq 1 \\
\sum_{t=1}^{T}\left(x_{\text {Poit }}-x_{\text {Poit }-1}\right) x_{\text {Poit }} \leq 1 \\
0 \leq W_{T t} \leq W_{T M A X} \\
W_{T t}=W_{T t-1}+\sum_{i=1}^{N}\left(-W_{\text {Lit }}+W_{\text {Sit }}+W_{\text {Pit }}+W_{\text {Git }}\right) \\
\sum_{i=1}^{N} P_{L O A D i t}-\sum_{i=1}^{N} p_{\text {Pit }}\left(x_{\text {Poit }}\right) \geq 0 \\
W_{N E X T}<W_{T 48}
\end{gathered}
$$

where, $\alpha$ : weighting factor $(0 \leq \alpha \leq 1), F(\alpha)$ : objective function of main problem for determining $\alpha$, $f\left(x_{\alpha}, p_{\alpha}\right)$ : objective function of partial problem, $F_{C O S T}\left(x_{\alpha}, p_{\alpha}\right), F_{C O 2}\left(x_{\alpha}, p_{\alpha}\right)$ : energy cost and $\mathrm{CO}_{2}$ emissions normalized by minimum value in results of partial problem, $f_{\text {cost }}\left(x_{\alpha}, p_{\alpha}\right), f_{\text {CO2 }}\left(x_{\alpha}, p_{\alpha}\right)$ : energy cost (yen) and $\mathrm{CO}_{2}$ emissions $(\mathrm{kg})$ in results of partial problem, $T$ : total number of time period, $P_{S Y S t}$ : purchasing power at time period $t(\mathrm{kWh})$, Cost $_{P}$ : electric power rate $(\mathrm{yen} / \mathrm{kWh}), N_{S}, N_{P}$ : total number of SOFCs and PEFCs, $G_{S i t}\left(x_{\alpha}, p_{\alpha}\right), G_{P i t}\left(x_{\alpha}, p_{\alpha}\right)$ : consuming city gas volume of SOFC $i$ and PEFC $i$ at $t\left(\mathrm{~m}^{3}\right)$, Cost $_{G}$ : city gas rate $(\mathrm{yen} / \mathrm{kWh}), P_{\text {SURt }}$ : surplus electric power at $t(\mathrm{kWh}), \operatorname{Cost}_{P S}$ : rate of selling electric power (yen/kWh), $K_{G}: \mathrm{CO}_{2}$ emissions conversion factor of fuel gas $\left(\mathrm{kg}-\mathrm{CO}_{2} / \mathrm{kWh}\right), x_{\text {Sait }}$, $x_{\text {Pait }}$ : operational state of SOFC $i$ and PEFC $i$ at $t$ (on $=1$, off $=0), p_{\text {Sait }}, p_{\text {Pait }}$ : output of SOFC $i$ and PEFC $i$ at $t(\mathrm{kWh}), K_{E}: \mathrm{CO}_{2}$ emissions conversion 
factor of purchased power $\left(\mathrm{kg}-\mathrm{CO}_{2} / \mathrm{kWh}\right), B_{\mathrm{CO} 2 i t}$ : $\mathrm{CO}_{2}$ emissions of boiler $i$ at $t(\mathrm{~kg}), N$ : total number of rooms, $P_{L O A D i t}$ : electric power demand at $t(\mathrm{kWh})$, $P_{S i t}, P_{P i t}$ : electric power consumption of SOFC $i$ and PEFC $i$ on start-up (kWh), $P_{S E L i t}$ : electric power of selling $(\mathrm{kWh}), W_{T t}$ : storage quantity of heated water at $t(\mathrm{~L}), W_{T M A X}$ : capacity of tank (L), $W_{L i t}$ : heated water demand at $t(\mathrm{~L}), W_{S i t}, W_{P i t}$ : productive heated water of SOFC $i$ and PEFC $i$ at $t(\mathrm{~L}), W_{G i t}$ : productive heated water of gas boiler $i$ at $t(\mathrm{~L})$, $W_{N E X T}:$ necessary quantity of heated water in next day (L).

Eq. (1) means the deviation from the minimum of normalized energy cost and $\mathrm{CO}_{2}$ emissions. Eq. (2) means summation of weighted value of normalized energy cost and $\mathrm{CO}_{2}$ emissions. Eqs. (3) and (4) mean energy cost and $\mathrm{CO}_{2}$ emissions normalized by the minimum of each value. Eq. (5) means the calculating formula of energy cost. Eq. (6) means the calculating formula of $\mathrm{CO}_{2}$ emissions. Eq. (7) means the constraint for electric power supply and demand that the summation of generation and purchasing or selling electric power must be equal to load demand. Eqs. (8) and (9) mean the constraint that FCs start once a day from viewpoints of life cycle and starting cost of FCs. Eq. (10) means the constraint for heated water storage tank. The heated water quantity does not exceed those capacities. Eq. (11) means the constraint for amount of the heated water in the tank. Eq. (12) means the constraint that the output of PEFCs must not exceed the load demand. Eq. (13) means the constraint of heated water carried over for the next day.

\section{Determination Method of Operation Schedule of SOFCs and PEFCs}

As Section 2.2 described, the determination problem of cogeneration operation schedule for FCs is a nonlinear optimization problem. It determines the start-and-stop of each FC and the output of each FC in each time period. Specifically, the operation schedule of FCs is determined using the tabu search [4] which is one of the optimization methods. Moreover, the tabu search is applied to the determination problem of start-and-stop schedule and output schedule of FCs. The determination procedure is shown below. The flowchart of the proposed method is shown in Fig. 4.

Procedure (1):

The energy cost and $\mathrm{CO}_{2}$ emissions of the optimal operation schedule are determined as $\min \left\{f_{\text {COST }}\right\}$ and $\min \left\{f_{\mathrm{CO} 2}\right\}$.

Procedure (2):

The initial solution and the iteration count $N$ are set up in the start-and-stop schedule of SOFCs and PEFCs.

Procedure (3):

From the present solution of the start-and-stop schedule of SOFCs and PEFCs, start-up and stop time are changed forward and backward, and these solutions will be created, as shown in Fig. 5. Specifically, eight kinds of these solutions exist (1) Start-up time is brought forward, (2) Start-up time is delayed, (3) Stop time is delayed, (4) Stop time is brought forward, (5) Start-up time is brought forward and stop time is delayed, (6) Start-up time is delayed and stop time is brought forward, (7) Start-up time and stop time are brought forward, (8) Start-up time and stop time are delayed). Some of these solutions which shifted these times are created.

Procedure (4):

The initial solution and the iteration count $M$ are set up in the output schedule of SOFCs and PEFCs.

Procedure (5):

The output of SOFCs and PEFCs is changed, and the neighborhood solutions are created. The outputs of SOFCs have fourteen patterns between $0.05 \mathrm{~kW}$ and $0.70 \mathrm{~kW}$ (step size $0.05 \mathrm{~kW}$ ), and PEFCs have eleven patterns between $0.20 \mathrm{~kW}$ and $0.70 \mathrm{~kW}$ (step size 0.05 $\mathrm{kW})$.

Procedure (6):

Solution of partial problem is calculated by Eq. (2). If output of SOFCs is higher than power demand, surplus electric power can be sold. 


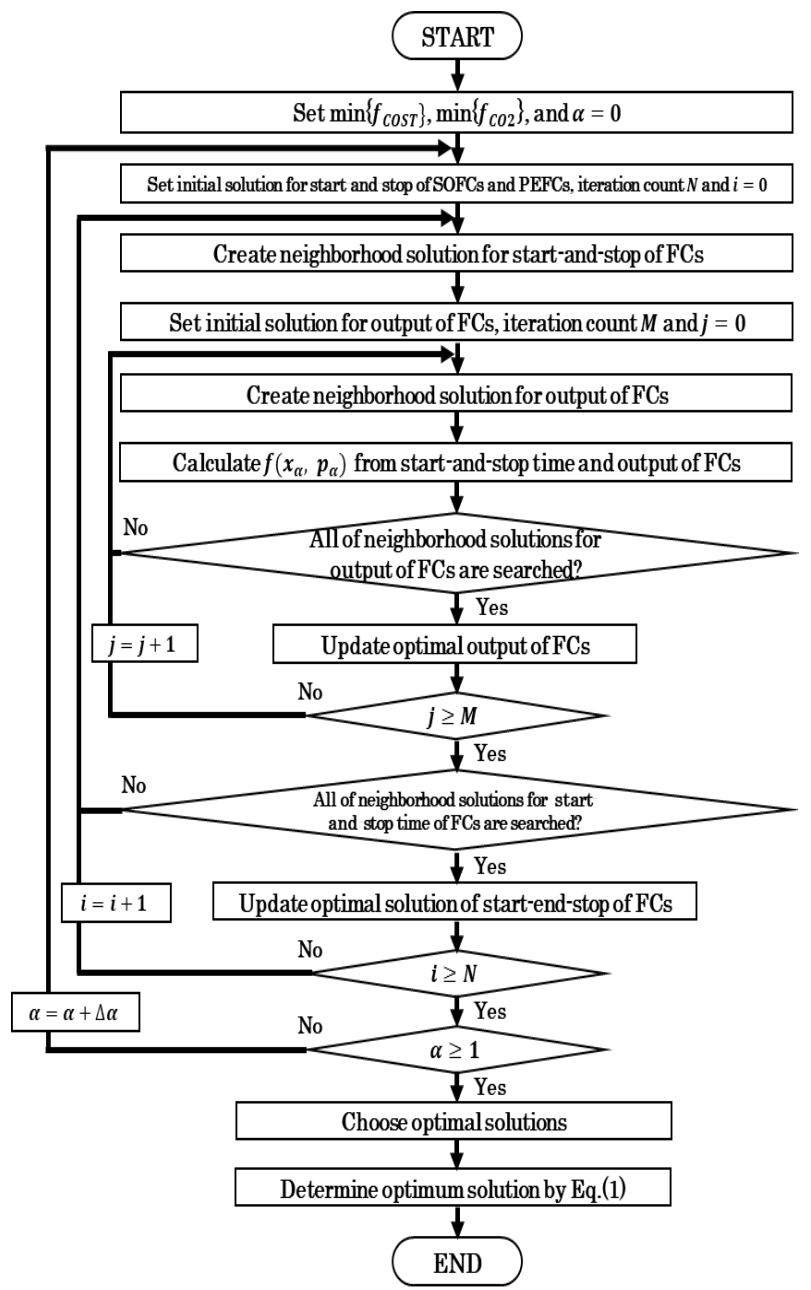

Fig. 4 Flowchart of operation schedule determination of SOFCs and PEFCs.

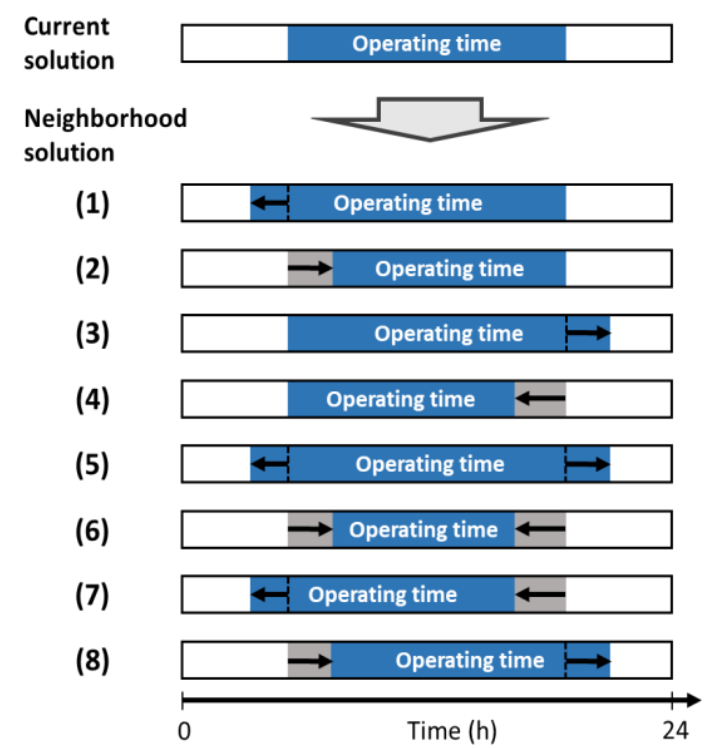

Fig. 5 Neighborhood solution for start/stop schedule of SOFCs and PEFCs.
Procedure (7):

If it searches for the neighborhood solution of all the output schedule of SOFCs and PEFCs, the present solution and the approximation optimal solution of the output schedule of SOFCs and PEFCs will be updated. Else if, return to Procedure (5).

Procedure (8):

If the iteration count of the output schedule of SOFCs and PEFCs amounts to $M$ times, search of the output schedule will be ended and it will progress to Procedure (9). Else if, return to Procedure (5).

Procedure (9):

If the iteration count of the output schedule of SOFCs and PEFCs amounts to $N$ times, search of the start-and-stop schedule will be ended and it will progress to Procedure (10). Else if, return to Procedure (3).

Procedure (10):

If it becomes $\alpha \geq 1$, search will be ended and it will progress to Procedure (11). Else if, the minimal change $\Delta \alpha$ is added to $\alpha$, and return to Procedure (2), where, $\Delta \alpha$ is the unit width of change of a weighting factor.

Procedure (11):

Pareto optimal solution is determined in the schedule of FCs as each $\alpha$.

Procedure (12):

The operation schedule that the evaluation index of Eq. (1) becomes the minimum is determined as an optimal operation schedule of SOFCs and PEFCs.

\section{Numerical Examples}

In order to verify the validity of the proposed cogeneration system, the numerical calculations are carried out for one unit of the collective housing model shown in Fig. 2. And the operation schedules of SOFCs and PEFCs for each season are decided by using the proposed determination method.

\subsection{Numerical Calculation Condition}

The authors assume the capacity of heated water tank in a unit is total of tank of two SOFCs and two 


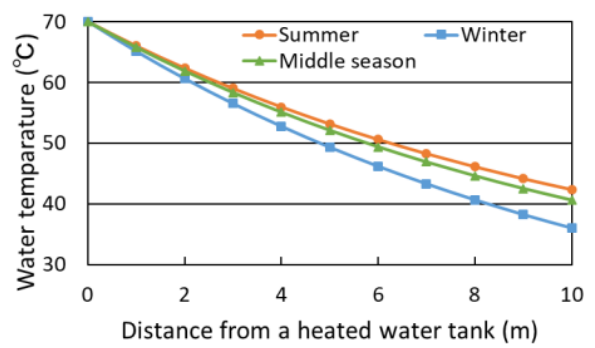

Fig. 6 Relationship between heated water temperature and distance from heated water tank.

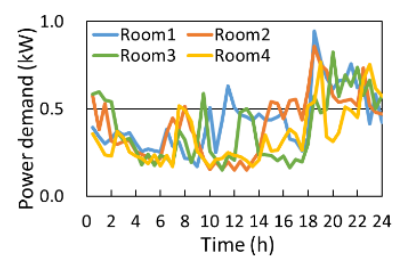

(a) Power demand

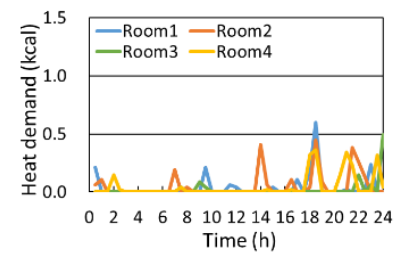

(b) Heat demand
Fig. 7 Load data of one day in summer.

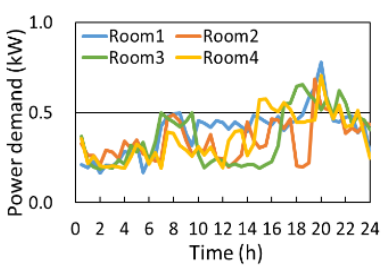

(a) Power demand

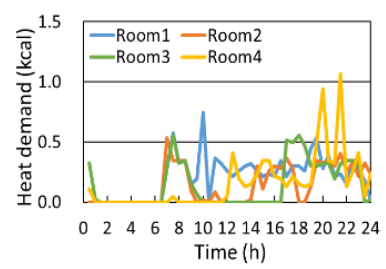

(b) Heat demand
Fig. 8 Load data of one day in winter.

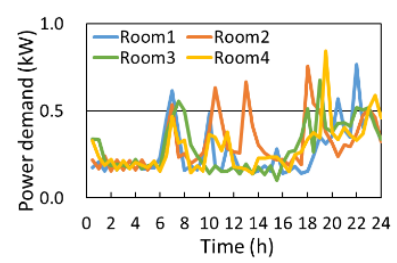

(a) Power demand

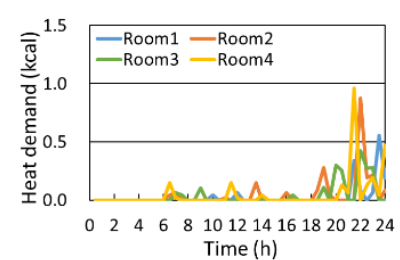

(b) Heat demand
Fig. 9 Load data of one day in middle season.

PEFCs. It shall assume that the heated water made on the previous day remains in the tank, the quantity of the heated water in the tank at the first time period of the day shall be 60 liters, and at the last time period of the day shall be also 60 liters or more.

Fig. 6 shows a calculation result of a relationship between drop of heated water temperature in a pipe and distance from the heated water tank. As shown in Fig. 6, in case the distance is three meters, the heated water temperature of $70{ }^{\circ} \mathrm{C}$ drops to $59.0{ }^{\circ} \mathrm{C}$ in summer, $56.5{ }^{\circ} \mathrm{C}$ in winter, and $58.3{ }^{\circ} \mathrm{C}$ in middle season. In case the distance is six meters, the heated water temperature drops to $50.6{ }^{\circ} \mathrm{C}$ in summer, $46.2{ }^{\circ} \mathrm{C}$ in winter, and $49.4{ }^{\circ} \mathrm{C}$ in middle season. From these results, if consumers use the heatedwater for a bath, it is found that the heated water can be interchanged through nearby houses. It is assumed that the width of one room in the collective housing is six meters and of the common space is two-three meters. In general, the neighboring rooms in the collective housing often allocate symmetrically. Hence, as shown in Fig. 2, the authors assume the pipe length is three meters between Room 2 and FCs (same applies to Room 3 and FCs), and six meters between Room 1 and FCs (same applies to Room 4 and FCs). The actual measurement data (30-minute value) in one weekday of summer (average temperature of $29.1{ }^{\circ} \mathrm{C}$ ), of winter (average temperature of $3.0^{\circ} \mathrm{C}$ ), and of middle season (average temperature of $16.2^{\circ} \mathrm{C}$ ) were used for load data. The family structure of each room is three persons. The power demand and heat demand data of each season which were used for the numerical calculations shown in Figs. 7-9. The specification of SOFC and PEFC system used by the numerical calculations is shown in Table $1[5,6]$. Table 2 [7] and Table $3[5,8]$ show the set values of electric power and city gas.

\subsection{Calculation Results}

The calculation results in each season are shown in Figs. 10-18. As shown in Figs. 10-12, the optimal

Table 1 Specification of FC systems.

\begin{tabular}{lll}
\hline & SOFC & PEFC \\
\hline $\begin{array}{l}\text { Output pattern }(\mathrm{kW}) \\
\begin{array}{l}\text { O.05-0.70 } \\
\text { (step size 0.05) }\end{array}\end{array}$ & $\begin{array}{l}0.20-0.70 \\
\text { (step size 0.05) }\end{array}$ \\
$\begin{array}{l}\text { hemperature of } \\
\text { heapacity of heated }\left({ }^{\circ} \mathrm{C}\right)\end{array}$ & 70 & 60 \\
$\begin{array}{l}\text { water tank (L) } \\
\text { Power generation } \\
\text { efficiency }(\%)\end{array}$ & 52.0 & 140 \\
$\begin{array}{l}\text { Efficiency of } \\
\text { exhaust heat } \\
\text { recovery }(\%)\end{array}$ & 43.5 & 36.9 \\
$\begin{array}{l}\text { Calorific value of } \\
\text { gas }(\mathrm{kW})\end{array}$ & 1.37 & 56.0 \\
$\begin{array}{l}\text { Efficiency of gas } \\
\text { boiler }(\%)\end{array}$ & 82 & 2.00 \\
\hline
\end{tabular}


Table 2 Set values concerning electric power.

\begin{tabular}{llll}
\hline & & With FC & Without FC \\
\hline Basic rate (yen) & 373.60 & 373.73 \\
\hline & $\begin{array}{l}0-15 \mathrm{kWh} \\
15-120 \mathrm{kWh}\end{array}$ & 22.75 & 0.00 \\
& & 22.83 \\
$\begin{array}{l}\text { Rate of electric power } \\
\text { quantity (yen/kWh) }\end{array}$ & $\begin{array}{l}120-200 \mathrm{kWh} \\
200-300 \mathrm{kWh}\end{array}$ & 25.10 & 29.19 \\
& $300-\mathrm{kWh}$ & 31.63 & 33.32 \\
\hline $\begin{array}{l}\text { Rate of selling electric power (only } \\
\text { SOFC) (yen/kWh) }\end{array}$ & 13.00 & \\
\hline $\begin{array}{l}\text { Conversion factor of } \mathrm{CO}_{2} \text { emission } \\
\text { (kg/kWh) }\end{array}$ & 0.507 & \\
\hline
\end{tabular}

Table 3 Set values concerning city gas.

\begin{tabular}{|c|c|c|c|c|}
\hline & & $\begin{array}{l}\text { With FC } \\
\text { (Apr.-Nov.) }\end{array}$ & $\begin{array}{l}\text { With FC } \\
\text { (Dec.-Mar.) }\end{array}$ & $\begin{array}{l}\text { Without } \\
\text { FC }\end{array}$ \\
\hline \multicolumn{2}{|c|}{ Basic rate (yen) } & 745.20 & & \\
\hline \multirow{4}{*}{$\begin{array}{l}\text { Rate of } \\
\text { city gas } \\
\text { quantity } \\
\left(\text { yen } / \mathrm{m}^{3}\right)\end{array}$} & $0-20 \mathrm{~m}^{3}$ & 191.14 & & \\
\hline & $20-50 \mathrm{~m}^{3}$ & & 161.53 & 161.53 \\
\hline & $50-100 \mathrm{~m}^{3}$ & 95.50 & 103.33 & 156.36 \\
\hline & $100-\mathrm{m}^{3}$ & & 101.11 & 152.10 \\
\hline \multicolumn{2}{|c|}{$\begin{array}{l}\text { Conversion factor of } \\
\mathrm{CO}_{2} \text { emission }\end{array}$} & $\begin{array}{l}\text { FC: } 0.491 \mathrm{~kg} \\
\text { Boiler: } 2.29\end{array}$ & $\begin{array}{l}\mathrm{kWh} \\
\mathrm{kg} / \mathrm{m}^{3}\end{array}$ & \\
\hline
\end{tabular}

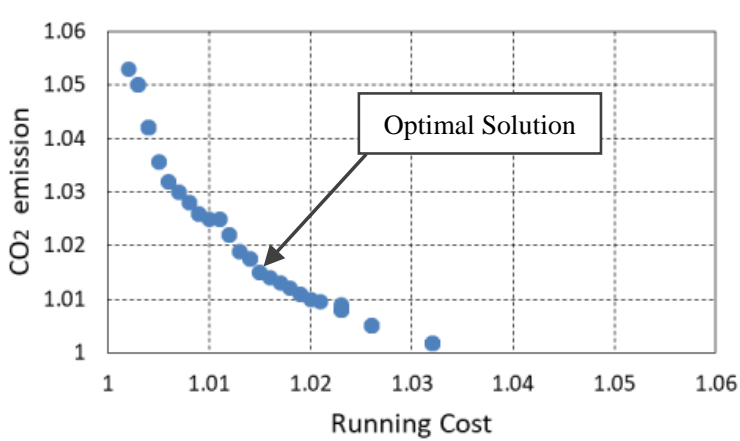

Fig. 10 Pareto optimal solution in summer.

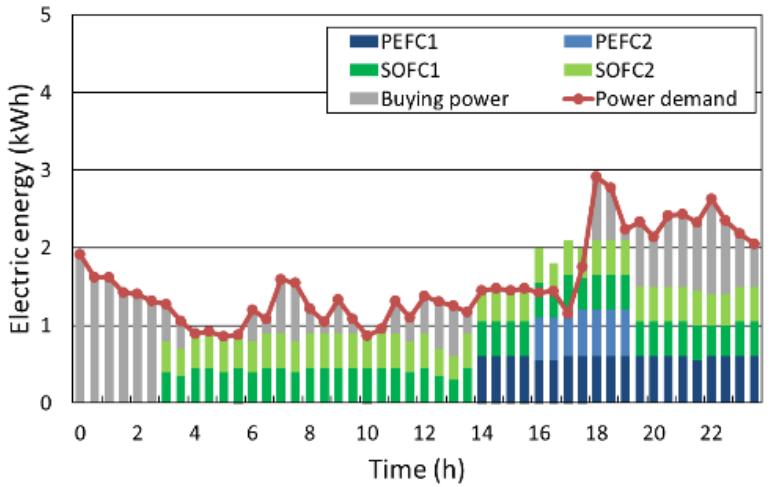

Fig. 11 Operation schedule of FCs in summer.

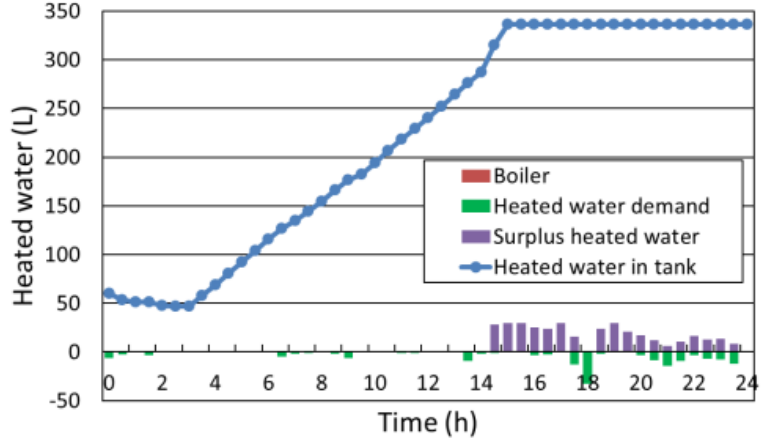

Fig. 12 Transition of heated water tank in summer.

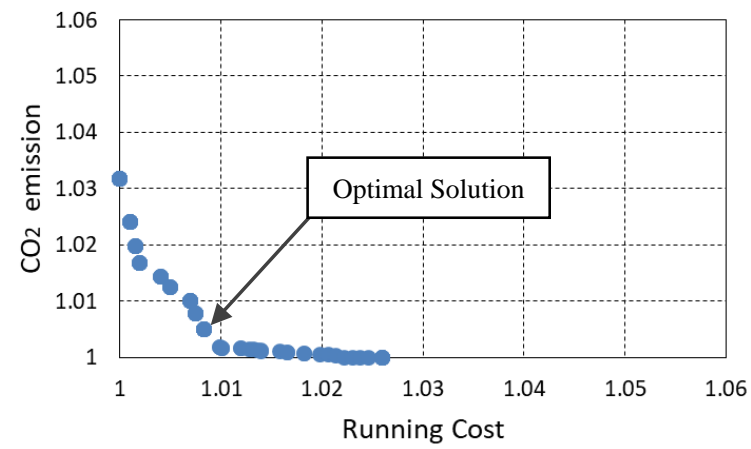

Fig. 13 Pareto optimal solution in winter.

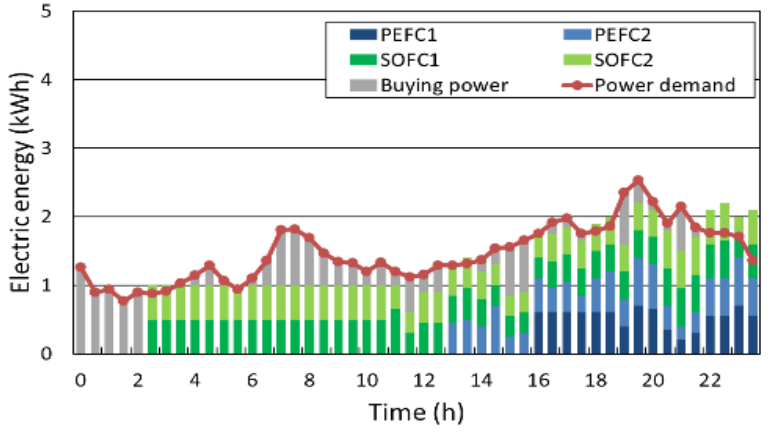

Fig. 14 Operation schedule of FCs in winter.

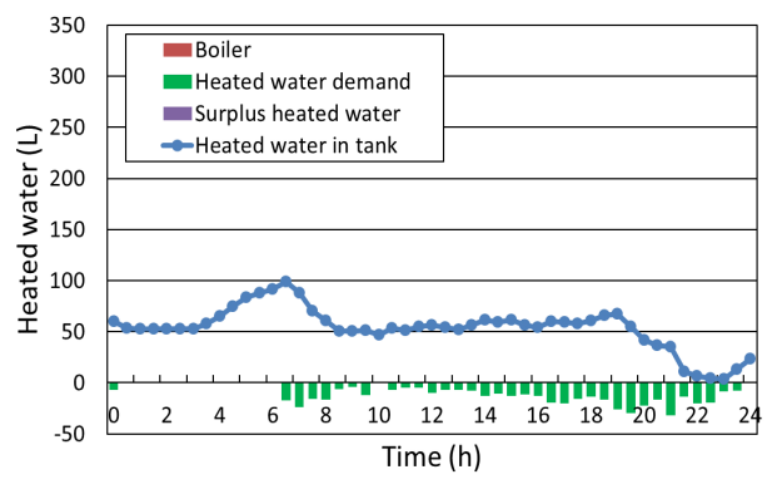

Fig. 15 Transition of heated water tank in winter. 
weighting factor of this schedule was $\alpha=0.62$ in summer. The outputs of SOFCs were based on the electric power demand. When the output of FCs exceeds the electric power demand, the consumers sell the surplus electric power. Moreover, it is assumed that the outputs of PEFCs are suppressed not to produce excess heatedwater which cannot be consumed by the washing machine. As shown in Figs. 13-15, the optimal weighting factor of this schedule was $\alpha=0.64$ in winter. The heated water demand is higher in winter than in other seasons. As shown in Figs. 14 and 15, FCs are used not to get low in all time. In particular, PEFCs which have high efficiency of exhaust heat recovery repair failure of the heated water. As shown in Figs. 16-18, the optimal weighting factor of this schedule was $\alpha=0.83$ in middle season. The heated water demand in middle season is similar in summer. Hence, FCs worked not to excess the heated water like in summer. In Pareto optimal solution, these elements are equally important about in summer and winter. $\mathrm{CO}_{2}$ emissions are more important than the energy cost in middle season.

Comparison of energy cost in each season and annual $\mathrm{CO}_{2}$ emissions are shown in Table 4. The energy cost means the average of four rooms for one month. In case four SOFCs are set, the energy cost is the most reduced in summer. In case four PEFCs are set, the energy cost is the most reduced in winter. On the other hand, it is considered that the proposed combined SOFCs and PEFCs system can provide the operation schedule considering both energy cost and $\mathrm{CO}_{2}$ emissions throughout the year.

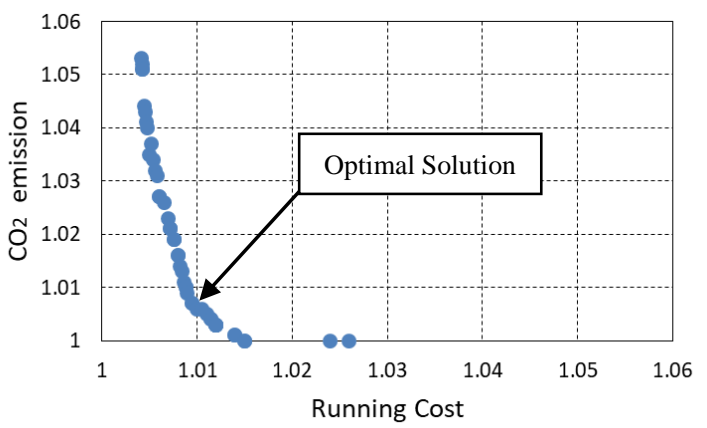

Fig. 16 Pareto optimal solution in middle season.

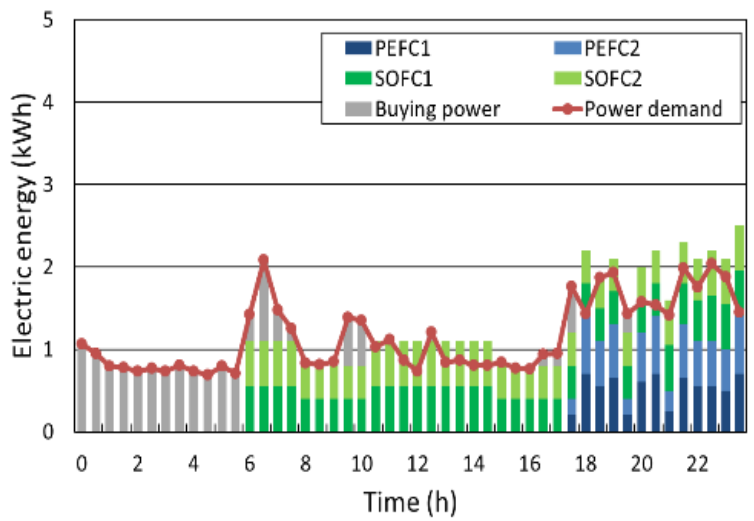

Fig. 17 Operation schedule of FCs in middle season.

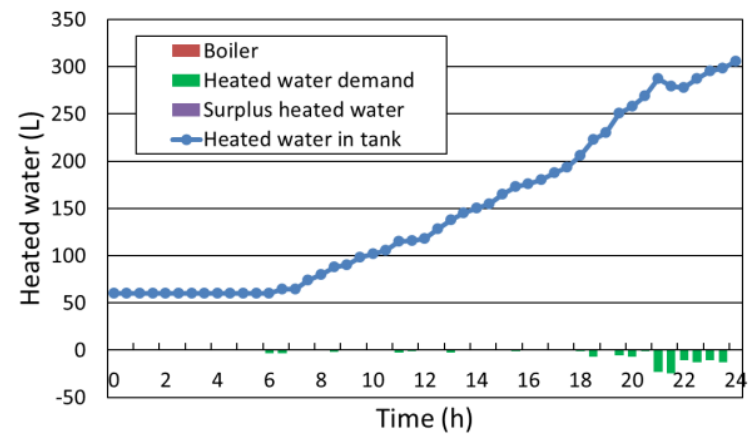

Fig. 18 Transition of heated water tank in middle season.

Table 4 Comparison of energy cost and $\mathrm{CO}_{2}$ emissions in one room.

\begin{tabular}{lllll}
\hline & $\begin{array}{l}\text { Summer } \\
\text { (yen/month) }\end{array}$ & $\begin{array}{l}\text { Winter } \\
\text { (yen/month) }\end{array}$ & $\begin{array}{l}\text { Middle } \\
\text { season } \\
\text { (yen/month) }\end{array}$ & $\begin{array}{l}\mathrm{CO}_{2} \\
\text { emission } \\
\text { ing a year }\end{array}$ \\
\hline $\begin{array}{l}\text { 2 SOFCs \& } \\
\text { 2 PEFCs }\end{array}$ & 11,312 & 11,004 & 7,788 & 2,151 \\
4 SOFCs & 8,581 & 16,249 & 7,768 & 2,061 \\
4 PEFCs & 12,078 & 9,971 & 7,906 & 2,205 \\
Without & 11,169 & 16,105 & 8,940 & 2,804 \\
FC & & & &
\end{tabular}

\section{Conclusions}

In this study, the authors proposed the electric power and heat interchange system by combining use of SOFCs and PEFCs in a collective housing. And the authors also proposed the determination method of cogeneration operation schedules from viewpoints of minimizing energy cost and $\mathrm{CO}_{2}$ emissions. The validity of the proposed system and determination method was shown from the results of numerical calculations for one unit (four rooms) of the collective housing. 
In the future, the authors are going to investigate about the optimum combination number of SOFCs and PEFCs and the capacity of heated water tank. In addition, the authors are going to expand the dimension of interchanging electric power and heated water.

\section{References}

[1] Inada, R., Sugihara, H., Saeki, O., and Tsuji, K. 2007. "Evaluation of Introducing Micro-cogeneration System to Residential Houses Based on the Monitored Daily-Basis Energy Demand Data." IEEJ Transactions on Power and Energy 127 (1): 9-18.

[2] Hayashi, Y., Kawasaki, S., Matsuki, J., Tomomoto, A., Miyamoto, H., Funabashi, T., Okuno, Y., and Hayashi, T. 2008. "Determination Method of Optimal Operation Schedule for Fuel Cells in Collective Housing."
IEEJ Transactions on Power and Energy 128 (10): 1217-26.

[3] Kameda, M., Fujimoto, Y., and Hayashi, Y. 2014. "Determination Method of Operation Plan for Fuel Cells in Collective Housing with Electric Power Interchange System." IEEJ Transactions on Power and Energy 134 (8): 682-91.

[4] Glover, F. 1989. "Tabu Search-Part I." ORSA Journal on Computing 1 (3): 190-206.

[5] The homepage of Osaka Gas. http://home.osakagas.co.jp/price/menu/profitable/p_01.ht $\mathrm{ml}$; https://wwwe5.osakagas.co.jp/custserv/ryokinhyo1001.ht $\mathrm{ml}$.

[6] The homepage of Tokyo Gas. http://www.tokyo-gas.co.jp.

[7] The homepage of Kansai Electric Power Company. http://kepco.jp/ryokin/menu/dento_a.

[8] The homepage of Ministry of the Environment. https://www.env.go.jp/press/files/jp/104428.pdf. 